\title{
OS MESTIÇOS MAIS PUROS. REPRESENTAÇÕES CHIRIGUANO E CHANÉ DA MESTIÇAGEM
}

Isabelle Combès e Diego Villar

\section{Três paradoxos}

Em 1908, Erland Nordenskiöld visitou várias comunidades dos índios Chiriguano e Chané no noroeste argentino e no Chaco boliviano. Não se mostrou muito otimista acerca de seu destino: "Não tenho grandes esperanças no futuro dos Chiriguano e Chané. Serão assimilados para formar o grosso da raça mestiça que no futuro dominará sem indígenas os bosques secos do vale do Parapeti e os últimos contrafortes dos Andes na direção do Grande Chaco" (2002 [1912]:275).

Segundo vários investigadores, a lúgubre previsão de Nordenskiöld verificou-se nos anos posteriores. Ao se referir à mestiçagem entre índios e brancos, o historiador boliviano Hernando Sanabria escreveu: “Quem quiser hoje encontrar chiriguanos na Cordilheira e no Chaco terá de procurar muito e nem sempre com êxito (nota a Moreno 1973:547). Para Thierry Saignes, esta mesma mestiçagem "esteve na origem da desorganização dos grupos chiriguano do século XIX" (1974:329); o mesmo autor destaca a "perda física, material e cultural" do mundo chiriguano e vê no século XX "a história de uma brutal 'desintegração' do mesmo" (1990:211, 221).

A decadência, a aculturação ou mesmo o desaparecimento físico devidos à mestiçagem com os brancos foram e são um lugar comum — desgraçadamente, muitas vezes certo - nos discursos sobre as etnias ameríndias; assim, este tipo de pessimismo não tem nada de novo. No entanto, a mestiçagem ameríndia não é um problema exclusivo de índios e brancos e tampouco começou somente com a chegada dos colonizadores; de fato, documentaram-se distintos processos pré-hispânicos de mistura étnica (Schwartz \& Salomon 1999). ${ }^{1}$ O caso chiriguano é, precisamente, um exemplo canônico de hibridismo e, conseqüentemente, os veredictos de sua morte ou desintegração por conta da mestiçagem motivam uma estranha série de paradoxos. 
OS MESTIÇOS MAIS PUROS

Todos concordam que os Chiriguano são uma etnia "essencialmente" mestiça. Nasceram no Chaco ocidental devido ao encontro de dois grupos ameríndios: os Chané, de origem arawak, e os Guarani, chegados em épocas pré-hispânicas ao pé do monte andino desde o Paraguai e o Brasil. Menos numerosos que os Chané, os Guarani, contudo, os dominaram politicamente, impuseram-lhes sua língua e sua cultura e se misturaram com eles. Os invasores desposaram mulheres chané ${ }^{2}$, deste modo, a segunda geração após a conquista foi composta por um alto número de mestiços "filhos deles e das índias de outras nações" (Suárez de Figueroa 1965 [1586]:404), assimilados à sociedade de seus pais através da "guaranização" lingüística e cultural e da integração de confrarias guerreiras. ${ }^{3}$ Segundo testemunho colonial, esses mestiços chegavam a ser "tão maus e piores que os legítimos e naturais" (idem:405). Os guerreiros indômitos que as crônicas chamavam de "chiriguanaes" eram definitivamente mestiços filhos dos amos guarani (yia) e de suas escravas chané (tapłï). Ao cabo de poucas gerações, os Chané desapareceram como grupo, fagocitados pelos Guarani e transformados para sempre em Chiriguano (Combès \& Saignes 1991).

Primeiro paradoxo, então: uma etnia nascida da mestiçagem e sentenciada à morte precisamente por causa de outra mestiçagem. Dos Chiriguano apenas restariam na atualidade os "cambas", nome dado aos mestiços e aos crioulos no oriente boliviano; de fato, os cambas contemporâneos e seu movimento político ultra-regionalista, a "Nação Camba", reivindicam hoje em voz alta sua condição mestiça. Mas os "chiriguano", como tais, pareciam não existir mais na Bolívia.

No entanto - segundo paradoxo - os Chiriguano, enterrados prematuramente pelos pesquisadores, existem, sim, como grupo étnico consolidado, mesmo que sob outro nome. Embora atualmente prefiram se chamar "guarani", não perderam por isso sua fama guerreira — de fato seu movimento de representação política seja talvez o mais forte das terras baixas bolivianas — nem seu idioma, ou muito menos sua importância demográfica: o censo nacional de 2001 lança uma cifra de quase 80.000 "guaranis" na Bolívia. Além de sua existência factual e do rótulo que eventualmente adotam para identificar-se, o caráter híbrido de sua identidade étnica não deixa de ser problemático. Sob o nome de "guarani" são conhecidos, na Bolívia, três grupos: os Ava, os Simba e os Isoseño, unidos pelo idioma, mas diferenciados por seus dialetos, trajetórias históricas e matizes culturais. ${ }^{4}$

A situação dos Chané, antigos sócios da mestiçagem, é ainda mais complexa. Apesar de terem sido "guaranizados", também seguem existindo. Na Bolívia, alguns se declaram "guarani", como os Chiriguano, e na região 
do Isoso*, "mais" guarani que eles; outros, nas margens do rio Itiyuro, no nordeste argentino, continuam chamando-se chané. Em que pese o idioma compartilhado, não se consideram parentes dos outros grupos de língua guarani da região. Neste sentido, o confuso e supostamente uniforme "complexo chiriguano-chané" existe apenas na visão um tanto simplista - e bastante redutora - de muitos pesquisadores. ${ }^{5}$

Terceiro paradoxo: trate-se de chané "guaranizados" ou de "guarani" ex-chiriguano, esses mestiços "em essência" não reconhecem ou muito menos reivindicam sua origem plural e mista. Chamem-se hoje chané ou guarani, seu nome só reflete a metade da história.

Existe definitivamente uma relação mais do que ambígua em relação à mestiçagem por parte dos Chiriguano, dos Chané e - por que não? - refletindo esse estado de coisas, por parte de seus pesquisadores. A ideologia subjacente a essa relação é precisamente aquela que procuraremos analisar. Sempre procurando não cair na armadilha do "complexo chiriguano-chané", esforçar-nos-emos para distinguir as situações singulares de grupos como os Chané do noroeste argentino e os Isoseño da Bolívia.

\section{De Chiriguano a Guarani}

Há 15 anos, um de nós publicava, em colaboração com Thierry Saignes, o livro Alter Ego. Naissance de l'identité chiriguano, logo traduzido para o espanhol, em 1995, sob o título Chiri-guana: nacimiento de una identidad mestiza. Ao enfocar a mestiçagem biológica e cultural entre Chané e Guarani, esta obra propôs também uma nova etimologia para a palavra chiriguana. Tal etimologia baseava-se em particular em uma nota escrita em 1586 pelo governador de Santa Cruz, que explicava que o termo "Chiriguanaes", "deriva de Chiriones, que quer dizer 'mestiços'" (Suárez de Figueroa 1965 [1586]:404). Os Chané, com quem se misturaram os migrantes do povo Guarani, também eram conhecidos pelo nome de Chaná. No Chaco oriental, onde conviviam com etnias Guaykuru, também foram "vulgarmente conhecidos pelo nome de guaná" (Sánchez Labrador 1910 [c.1770], t.II:255). Conseqüentemente, propunha-se interpretar o termo "chiriguana", parafraseando Suárez de Figueroa, como "filhos de guarani com índias chané ou guana" (Combès \& Saignes 1991:53-54).

\footnotetext{
* [N.T.]. O Isoso é a região do Chaco Boliviano próxima do rio Parapetí, que, por sua vez, nasce nos Andes, atravessa o Chaco e, após confluir com alguns outros rios, deságua no rio Paraguai.
} 
Correta ou errônea, essa etimologia tinha ao menos a vantagem, para os próprios "chiriguanos", de deixar de lado outras tão popularizadas quanto depreciativas. Com efeito, até hoje continuam vigentes certas exegeses duvidosas que procuram derivar o nome "chiriguano" do quéchua. Segundo versões que retomam amiúde antigas interpretações coloniais, os "chiri-guano" são os "castigados pelo frio" (chiri), porque foram feitos prisioneiros pelos Inca e expostos à intempérie, nus, no alto de um monte nevado; alguns atribuem o castigo apenas ao clima rigoroso do pé de monte andino; outros, enfim, explicam simplesmente que chiri-guano significa em quéchua "guano" (excremento) frio. ${ }^{6}$ Em que pese a precariedade dos raciocínios que a sustentam, esta etimologia continua sendo a mais difundida tanto na Bolívia quanto no noroeste argentino. ${ }^{7}$ Como acontece nos atuais movimentos de reivindicação étnica e de revalorização cultural indígena, poder-se-ia esperar uma boa acolhida para a "reabilitação" semântica do termo proposta em Alter Ego. No entanto, isto não ocorreu. Ainda que ninguém a tenha refutado formalmente, o certo é que tampouco foi adotada sem reservas. Francisco Pifarré, Bartolomeu Meliá e Xavier Albó inauguraram uma série de pesquisas sobre "os guarani-chiriguanos", adotando programaticamente esta etimologia, mas sem eliminarem o rótulo de "guarani". Além dessa aceitação parcial, praticamente não usam a palavra "chiriguano" em seus escritos (Meliá 1988; Pifarré 1989; Albó 1990).

Quanto aos próprios Chiriguano, continuam rejeitando esse rótulo. Como o proclama sua organização política, os membros da Assembléia do Povo Guarani se declaram Guarani e somente Guarani. Tão Guarani que apagam de sua memória toda referência à antiga mestiçagem com os Chané que, nesta lógica homogeneizante, não existem, nem parecem haver existido nunca. Alguns Isoseño letrados — antropólogos, missionários e/ou organizações de desenvolvimento - aprenderam a palavra "arawak" em livros de antropologia e interpretam o termo como ara igua, literalmente, "os do céu" ou "os que vieram do céu". Os Arawak foram talvez antepassados, mas em todo caso antepassados guarani. Mais ainda: na região do Isoso, a mais chané de todas as regiões guarani da Bolívia, reinterpreta-se o nome

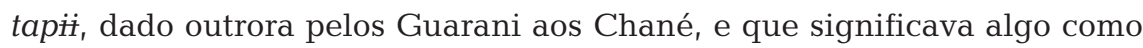
"escravo". Os Isoseño continuam sendo chamados tapï pelos Ava. Em sua interpretação atual, porém, um tapii já não é um escravo; é um guarani mais puro, mais autêntico - "mais verdadeiro" — que os demais. Em uma passagem célebre, Saignes evocou o voluntário "esquecimento" da tradição por parte dos Chiriguano contemporâneos (1990:219). No entanto, tudo sugere que se trata de um processo de construção e reinterpretação ideológica da história coletiva, e o silêncio estratégico se deve antes a um esquecimento 
parcial, a uma opacidade fragmentada e sobretudo seletiva. ${ }^{8}$

A atual negação ideológica da mestiçagem parece confirmar, em uma primeira instância, a tese de Alter Ego. Com efeito, o livro não apenas fala da mestiçagem entre Chané e Guarani, como também da escravidão suportada pelos primeiros nas mãos dos segundos. Esta escravidão está bem documentada nas fontes e teve vários matizes. Polo de Ondegardo indica, no século $\mathrm{XVI}$, que os Chiriguano "se servem deles [os Chané] em suas necessidades [...] estes lhes fazem suas granjas e semeaduras" (1914 [1574]:83-84). Pouco mais tarde, Lizárraga nota que os Chiriguano "se aproveitam [dos Chané] para o serviço de suas casas e semeaduras" (1968 [c.1600]:84). Esta situação generalizada logo levou todos os cronistas espanhóis a traduzirem tapii como "escravo". Os serviçais chané eram, também, as vítimas preferenciais do canibalismo ritual chiriguano, a ponto de os espanhóis temerem pelo desaparecimento dos "naturais". A partir de finais do século XVI, e com mais força nos séculos seguintes, os Chané continuaram sendo capturados pelos Chiriguano para serem vendidos aos colonos espanhóis. ${ }^{9}$

Ao adotar um modelo dumontiano (Dumont 1966) para conceitualizar a assimetria, Alter Ego argumenta que, embora os Chiriguano nasçam da união de ambos os grupos, os termos que compõem o casal não se vinculam em situação de igualdade. Ao descrever o encontro histórico entre ambos os grupos, utilizam-se expressões como negação da reciprocidade, circulação de influxos em sentido único, absorção dos Chané e, inclusive, predação "canibal" no estilo tupi-guarani. Trata-se, em todo caso, de um hibridismo hierárquico que combina seus elementos em doses diferentes e proporções desiguais, uma mestiçagem que estrutura uma relação de complementaridade assimétrica - em alguns grupos ameríndios, entre eles, os Chané e os Chiriguano - como a que costuma reger as relações entre os sexos. ${ }^{10}$ Os níveis mais inclusivos da sociabilidade e da política reproduzem simbolicamente, com efeito, as tensões e os contrastes próprios das relações de gênero. Os Chané são "homens de nenhum valor, bons para ofícios de mulher" (Nino 1912:279), condenados a uma posição ao mesmo tempo feminina e inferior. Na mestiçagem, o componente guarani e masculino domina o elemento feminino e chané, seja escravizando-o, desposando-o ou "guaranizando-o" (Combès e Saignes 1991:cap.3).

Nestas circunstâncias, a rejeição atual da condição mestiça por parte dos Guarani parece indissociável de outra rejeição: a antiga escravidão dos Chané. ${ }^{11} \mathrm{O}$ ideal guarani de iyambae, "sem dono", não se acomoda a um passado de escravidão degradante; como tampouco parece compatível com a idealização das sociedades indígenas "igualitárias" proposta hoje por antropólogos, movimentos étnicos e organizações de desenvolvimento. 
Na onipotência da identificação guaranizante também pode ter influído a "guaranização" sofrida pelos próprios pesquisadores que, em geral, apenas realçaram a dimensão guarani em detrimento da herança arawak (Combès e Lowrey 2006) ${ }^{12}$. No entanto, em um nível mais profundo, a supressão ideológica do hibridismo parece responder à assimetria fundadora que forjou a identidade étnica do grupo. Ao "guaranizar" os Chané e dominá-los, ao mesmo tempo em que se uniam com suas mulheres, os Chiriguano nasceram nos tempos pré-hispânicos e coloniais como mestiços, mas precisamente negando sua origem mista nos discursos e nas representações. Parece lógico, nessas circunstâncias, que apenas hoje reivindiquem sua condição de guarani - ou, em outras palavras, sua posição superior no par guarani/chané.

\section{Eu satisfeito por ser Chané ${ }^{13}$}

No final do século XVIII, com a mestiçagem consumada, o destino dos Chané parecia selado. Desapareceram como etnia, transformaram-se em Chiriguano, e sua lembrança elusiva aflora somente em vestígios da cultura material: as máscaras, as técnicas de rega e de tecer, os estilos de olaria. Esta perspectiva é correta em suas linhas gerais. No entanto, 15 anos depois parece-nos incompleta, quem sabe vítima inconsciente do imperialismo "guaranizante" que acomete em maior ou menor medida a etnologia chiriguano. Quando centramos o olhar nos Isoseño bolivianos e nos Chané argentinos, é possível matizar, relativizar, atualizar algumas das conclusões de Alter Ego.

A "guaranização" dos Chané certamente existiu, mas desenvolveuse paralelamente a uma "chaneização" dos Guarani que foi muito mais profunda e duradoura do que então se imaginava, atualmente perceptível além da cultura material. Por exemplo, dedicamos recentemente estudos comparativos à organização sociopolítica chiriguano e chané destacando seu indiscutível influxo arawak (Combès \& Villar 2004, Combès \& Lowrey 2006). As linhagens de caciques chané e isoseño ainda transmitem bens materiais e simbólicos, mantendo uma relação privilegiada com a língua, a memória coletiva e a conceitualização do espaço e do tempo. Os capitães sabiam e ainda sabem explorar à perfeição o jogo das alianças, administrando com maestria as redes de parentesco para obter vantagens políticas. Apelam, segundo as circunstâncias, para diversas estratégias de abertura da rede de afins (poliginia dos líderes, nomeação de parentes como capitães subalternos) ou de contração da mesma (matrimônio avuncular, repetições de alianças). Conseguem - ao se servirem alternativa e seletivamente da hipergamia e da hipogamia, da exogamia e da endogamia, do direito de sangue ou do 
direito de escolha, da descendência e da aliança, da patrilinearidade do cognatismo ou da matrilinearidade - traduzir conflitos políticos, queixas econômicas, disputas pelo poder e reivindicações étnicas ou territoriais em uma linguagem única, totalizadora, compreensiva, que constrói uma legitimidade concebida em termos de pureza étnica parentesco e aliança.

Tanto entre os Chané como entre os Isoseño, constata-se uma ideologia muito explícita da estirpe, da ascendência, do nível, da genealogia, da hierarquia e da consangüinidade real ou fictícia; afirma-se que a pertença à elite é uma questão de "sangue", de "pureza", de "herança" ou mesmo de "raça". Os Isoseño falam de ñemunia ete (engendra/reproduzir + sufixo de intensidade) ou anete ñemunia, "a família verdadeira" - termos que se traduzem em espanhol como "família real". As garantias tradicionais dessa "pureza" étnica eram, precisamente, as linhagens de caciques, decididamente endogâmicas na ideologia coletiva mais notória nos últimos rincões chané da Chiriguania. Essa tendência, não obstante, encontra-se vigente em todas as zonas "guarani" da Bolívia. Susnik notava, assim, a presença de uma "certa consciência da pureza ava, particularmente na categoria dos caciques" (1968:38). Porém, mais interessante ainda, tudo indica que esta ideologia da estratificação social, tão estendida entre os "guarani", é uma instituição de origem arawak. ${ }^{14}$ Não se trata de um fenômeno limitado ao testemunho etno-histórico, mas que repercute cotidianamente em contextos como a reivindicação étnica, a estruturação da história oral e da memória coletiva, a reciclagem onomástica ou o reconhecimento genealógico (Combès 2005; Combès \& Villar 2004; Bossert \& Villar 2004a e 2005).

O postulado da completa absorção dos tapï, ademais, não leva em conta uma realidade factual ineludível: a formação precoce de verdadeiros "rincões" chané, compostos por tapii "guaranizados" que escaparam das garras de seus senhores e continuaram definindo-se como chané. Esses assentamentos são claramente identificáveis. Trata-se, primeiro, da zona do Isoso na província Cordilheira, na Bolívia, povoada em meados do século XVI pelos Chané que fugiram dos Chiriguano do Gran Parapeti; de fato, os Isoseño foram conhecidos como "chané do Parapeti" até princípios do século XX. Outro rincão chané foi o do rio Acero, no departamento boliviano de Chuquisaca, povoado em meados do século XVIII por Chané de Saypurú desejosos de escaparem dos Chiriguano e que pediram, por esse motivo, o apoio da Audiência de Charcas. A esse núcleo pertencia precisamente o chefe Chindica, que nos dá o título desta seção.

Um terceiro grupo formou-se no vale do Caipependi, às margens do Pilcomayo, em uma data que resta por investigar. O último núcleo, finalmente, não é outro senão o assentamento do rio Itiyuro, no atual noroeste 
OS MESTIÇOS MAIS PUROS

argentino, cuja existência foi comprovada em fins do século XVIII, ainda que seja, provavelmente, muito mais antigo. ${ }^{15}$ Vários desses núcleos foram férreos opositores dos colonizadores espanhóis, mas também dos Chiriguano; em certas ocasiões, mantiveram contatos entre si, o que convida a pensar na existência de "redes chané" na Chiriguania colonial (Combès 2004a).

Na atualidade, subsistem só dois desses grupos: o do Isoso, na Bolívia, e o das margens do Ityuro, na Argentina. Os povoadores do rio Acero desapareceram em conseqüência das guerras de independência, dispersando-se ou talvez mimetizando-se com a população crioula [criolla] circundante; nas mesmas datas, também os Chané de Caipependi deixaram de aparecer na documentação histórica.

Últimos rincões chané, o Isoso e o Itiyuro têm então a mesma origem étnica e partilham uma história comum: a fuga ante seus antigos senhores chiriguano. Partilham também um mesmo idioma guarani, com suaves variações dialetais (Dietrich 1986). No entanto, recorrendo à expressão consagrada, as situações simétricas de ambos os núcleos podem ser pensadas como inversas. Os Isoseño atuais, como vimos, autodenominam-se "guarani" e negam categoricamente sua herança chané: a reinterpretação do termo "arawak", citada acima, é uma mostra clara da posição dos intelectuais isoseño. Os Chané argentinos, pelo contrário, rejeitam o rótulo "guarani" e continuam afirmandose como chané; apesar do idioma e dos costumes partilhados, consideram-se diferentes de seus vizinhos do "complexo chiriguano-chané", sejam Isoseño, Chiriguano ou Tapiete; lembram antigos enfrentamentos bélicos com eles e, até o momento, negaram-se obstinadamente a afiliar-se à Assembléia do Povo Guarani.* Para afirmar melhor sua diferença, declararam-se autóctones e argentinos em contraposição aos "chiriguanos" — leia-se, todo adventício de fala guarani chegado desde a Bolívia (Bossert \& Villar 2005).

Da perspectiva boliviana, chama a atenção que os povoadores do Itiyuro sejam os únicos que continuam - como outrora Chindica — "satisfeitos por serem chané". Sugerimos a identificação unânime como "guarani" dos Chiriguano e dos Isoseño da Bolívia, que pode ser lida como uma confirmação das teses desenvolvidas em Alter Ego sobre a absorção total dos Chané e a assimetria fundadora da sociedade chiriguano. Reforça a presunção o fato de que os Isoseño, descendentes de Chané, se declarem inclusive "mais guarani" que os demais. Mas é evidente que o exemplo dos Chané do noroeste argentino questiona esse modelo, ou ao menos sugere que o problema da

* [N.T.]. Assembléia fundada em 1987 a partir de reuniões iniciadas em 1986, das quais participaram líderes das comunidades guarani, das capitanias. Seu objetivo inicial era criar uma representação do povo Guarani. 
interpretação ideológica da mestiçagem não pode ser tão simples.

Tudo ocorre como se, ao declarar-se "somente" guarani ou "somente" chané, o que rejeitam tanto os Ava quanto os Isoseño e os Chané é a própria idéia da mistura, do sincretismo e do hibridismo. Em ambos os países, aqueles indígenas considerados "cruzados" ou "mesclados" não são bem-vistos pelos demais. Com desprezo a custo dissimulado, os Isoseño consideram como "meio guarani" seus conterrâneos estabelecidos nos arredores da cidade de Santa Cruz de la Sierra, amiúde unidos em matrimônio com Chiriguano de outras zonas, inclusive com outros indígenas (Combès et alii 2003). No nordeste argentino, da mesma forma, os Chané tradicionais, autoqualificados como "puros", distinguem-se dos Chiriguano ou dos Tapiete, seus parentes lingüísticos, já que também o fazem como outros grupos étnicos chaqueños (Toba, Chorote, Wichi). Nascidos da mestiçagem, os Chané e os Isoseño não só a renegam como a denigrem, diluem-na em uma retórica artificiosa da pureza e utilizam-na como argumento de discriminação interétnica. Definitivamente, a rejeição do legado chané por parte dos Chiriguano bolivianos bem pode corresponder à assimetria fundadora de sua sociedade, ou ainda à absorção "canibal" do elemento arawak em sua cultura. Mas a negação mais generalizada da mestiçagem em si, do próprio fato da mistura, da ênfase na "pureza", corresponde inversamente a uma ideologia chané que até hoje impregna a totalidade da estrutura política da sociedade chiriguano (Combès \& Villar 2004; Combès \& Lowrey 2006).

\section{"Ava e karay"16... e yanaigua}

Interlocutores preferenciais dos invasores guarani, os Chané não foram, contudo, seus únicos sócios no período pré-hispânico, nem na aurora da Colônia. Ainda que em menor escala, outros grupos étnicos chaqueños foram por sua vez escravizados e "guaranizados", por exemplo, os chamados Tapiete (tapï̈-ete: "verdadeiros tapï̈", "muito tapï̈"), usualmente considerados como Wichi (mataco) ou Chorote "guaranizados"17. Na atualidade, apesar dos ideais de "pureza étnica", os casamentos interétnicos - mesmo não constituindo a regra - não são raros. O casamento preferencial continua sendo o que une duas pessoas de um mesmo grupo étnico - nas palavras dos indígenas, de uma mesma raça. Logo, existem três tipos de uniões que os próprios indígenas qualificam como "cruzadas" ou "mescladas"18.

Primeiro, e mais freqüente, é o casamento misto que une cônjuges de diferentes grupos de idioma guarani (entre Ava e Isoseño, Chané e Ava etc.). Dadas as diferenças sentidas entre os diferentes grupos englobados sob o nome 
OS MESTIÇOS MAIS PUROS

"chiriguano" é legítimo qualificar esse tipo de união como interétnico; no entanto, certamente o idioma e os costumes compartilhados reduzem a diferença a um nível mínimo — daí, sem dúvida, seu maior êxito. O segundo tipo é entre membros de diferentes etnias: registramos no Isoso e no noroeste argentino, por exemplo, alguns escassos casamentos entre Isoseño e Ayoréode, Chiriguano e Wichi, ou Chané e Toba-pilagá, ou seja, com cônjuges indígenas pertencentes a outras famílias lingüísticas. ${ }^{19} \mathrm{O}$ terceiro tipo, muito mais freqüente que o segundo, é entre Chiriguano, Isoseño ou Chané e um cônjuge branco (karai).

Como são valorados esses diferentes tipos de aliança interétnica? Como revelam as observações citadas no início destas páginas, para a maioria dos pesquisadores os casamentos entre indígenas e brancos são pouco menos que uma calamidade; o signo de uma aculturação fatal que não tem remédio. As instituições estatais e privadas de desenvolvimento partilham desta opinião e se recusam amiúde a trabalhar com indígenas urbanos que "já não são indígenas". Trata-se, sem dúvida, de outro paradoxo, pois esses mesmos analistas não manifestam reparo algum em relação à mestiçagem pré-hispânica entre Chané e Guarani que, no entanto, também se desenvolveu em termos de dominação, aculturação, tendo inclusive como pano de fundo a prática do canibalismo ritual. A retórica da "autenticidade", a discriminação espúria entre mestiçagens próprias e impróprias, o juízo de valor acerca do que é, no fundo, um mesmo processo de mistura interétnica revelam apenas uma nostalgia inconsciente pelo Bom Selvagem.

Quanto aos próprios Chiriguano, Isoseño e Chané, sua valoração dos casamentos interétnicos parece muito mais matizada e situacional. O jogo relativo de diferenças étnicas se traduz na práxis da aliança matrimonial e no estabelecimento de fronteiras e distâncias relativas, e se liga com a abertura seletiva das redes de parentesco. Nordenskiöld notava, em 1908, que um homem chiriguano bem pode "divertir-se" com uma mulher chorote; "mas não a tomaria como esposa: seria demasiadamente idiota". Apontava também: "seria absurdo e ridículo que um chiriguano trabalhasse para um tapiete, tão inverossímel como uma moça chiriguana ser amante de um sujo choroti" (2002 [1912]:282). Poucos anos mais tarde, Métraux observaria: "nunca uma mulher chiriguana contrairá enlace com um toba ou outro índio chaqueño: seria para ela uma desonra inaudita ter relações com gente que os chiriguano qualificam desdenhosamente de "índios'" (1935:421).

O que aflora dessas observações não é (ou não é apenas) o juízo de valor dos etnólogos, mas também a própria conceitualização indígena das relações interétnicas. ${ }^{20}$ Os Chorote, como os Mataco, os Tapiete, os Ayoréde ou qualquer um dos demais povos chaqueños são yanaigua para os Chiriguanos e os Chané. O termo significa literalmente "os que vivem no bosque"21 e uma 
tradução adequada seria "bárbaro" ou "selvagem" (Combès 2004b).

Um casamento estável — para além da simples diversão sexual — com um yanaigua não só é malvisto como é praticamente impensável. De fato, como dissemos, essas uniões "cruzadas" são extremamente raras e costumam ser severamente julgadas pelas comunidades mediante acusações de folgança, debilidade, sujeira e bruxaria. Como no caso da antiga mestiçagem entre os Chané e os Guarani, a união interétnica é pensada em função de um modelo assimétrico que reproduz a ideologia das relações de gênero. A tendência geral da aliança, em termos mais abstratos, é que o cônjuge seja eleito entre os iguais étnicos ou, em todo caso, apelando para a eventual hipergamia feminina e a correspondente hipogamia masculina. Um rapaz pode desposar uma mulher de um grupo que ocupa um lugar inferior na escala de preferências, mas não o contrário. Em cada nível da escala, os "superiores" tomam mulheres dos "inferiores", o que equivale dizer que se encontrarão rapazes chiriguano ou chané com mulheres yanaigua, mas dificilmente o inverso. Como reflete a citação de Nordenskiöld, o homem chiriguano bem pode "divertir-se" com uma chorote; mas que uma mulher chiriguano seja amante de um chorote é tão impensável como era em tempos pré-hispânicos um hipotético casamento entre um homem chané e uma mulher ava: "é uma evidência para os chiriguano: não se casam com qualquer pessoa" (Combès \& Saignes 1991:57).

Nessas circunstâncias, compreende-se porque a aliança matrimonial com karai, pesadelo de muitos analistas, não é mal acolhida pelos próprios indígenas. Tanto na Bolívia quanto na Argentina, a estatística de casamentos interétnicos demonstra que o branco é sistematicamente mais escolhido do que os outros indígenas chaqueños. O modelo assimétrico segue em jogo, mas neste caso invertendo a valoração e colocando os brancos na posição superior. Este fato encontra amplo respaldo em diversos contextos da cosmologia e da história chiriguana e chané. Na Colônia, os karai gozam de um status altamente valorado: "Estimam ser a melhor gente do mundo exceto os espanhóis e por este motivo os reverenciam" (Matienzo 1922 [1561]:55; grifos nossos). O próprio nome karai evoca algo extraordinário, "quer dizer hábil, astuto, sagaz" (Comajuncosa \& Corrado 1884:38) ${ }^{22}$

Na atualidade, a complexidade social e a mestiçagem problematizam-se ideologicamente. Isto, por outro lado, permite relativizar a idéia romântica de uma sociedade indígena indefesa, sitiada pelas forças irresistíveis da colonização. A história dos Chiriguano, Chané e Isoseño contradiz a oposição simplista entre "brancos" e "indígenas" que deslumbra antropólogos, movimentos de representação e projetos de desenvolvimento. No plano da práxis, abundam episódios em que Chané e Isoseño não vacilam em se aliar 
OS MESTIÇOS MAIS PUROS

aos brancos contra os Chiriguano, seus inimigos tradicionais. De fato, tudo indica que em muitos casos o final de sua subordinação foi precisamente conseqüência dessas alianças. O plano das representações expõe a mesma ambivalência. Se nos mitos os karai costumam constituir um bloco arquetipicamente definido por sua riqueza e sua tecnologia (Villar 2005), na história oral, missionários, militares e fazendeiros também são representados como atores concretos e individuais, muitas vezes aliados, associados a melhorias reais na alimentação, na educação, na tecnologia, no estatuto jurídico ou nas condições de saúde.

Junto com a perda progressiva do território, o declínio do poder guerreiro, a experiência da exploração e os maus tratos nos engenhos e nas fazendas, existe outra idéia recorrente, segundo a qual o desenvolvimento histórico é concebido mediante uma notória ênfase progressiva. Esta ênfase cristaliza-se na tradicional fórmula narrativa arakae mbaetí, "antes não havia...", com a qual se iniciam freqüentemente os relatos da história oral. Não se trata de um mero anseio pelos bens materiais: a roupa karai condensa a possibilidade de lidar com o mundo exterior em pé de igualdade. As coisas representam valores que não só definem cada grupo social, mas determinam a própria natureza de suas vinculações recíprocas. Por trás do interesse em partilhar a língua, o alimento ou os costumes dos brancos, encobre-se o afã concreto de expandir o horizonte da sociabilidade ou, em outras palavras, mais do que a utilidade intrínseca dos bens plasma-se um interesse pelas relações sociais que sua própria circulação estabelece (Mauss 1980 [1924]; Hugh-Jones 1988:145; Gow 2001) 23. Os casamentos com os brancos, então, seguem a lógica tradicional da união assimétrica, ainda que em sentido inverso: os indígenas são os que ocupam a posição de doadores de mulheres. No noroeste argentino, há famílias chané cujas filhas se casam em série com cônjuges crioulos, mas não o contrário; e em Santa Cruz e arredores, a porcentagem de mulheres chiriguano casadas com karai é nitidamente superior a dos homens ava na mesma situação (Combès et alii 2003:61,68).

Voltamos então aos vaticínios equívocos sobre o ocaso chiriguano devido à mestiçagem. Em um extremo, o modelo exposto não implica de modo algum que mediante sua hipergamia - que é eventual, contextual, seletiva e deve ser entendida no conjunto total das alianças interétnicas os indígenas procurem "tornar-se karai". Tampouco, no outro extremo, que a aliança com o branco não seja problemática. $O$ fato de a relação não ser inteiramente negativa não implica que não esteja tingida de uma forte ambivalência. Os ikaraipota (lit. "o que gosta dos karai") costumam não ser bem-vistos nas comunidades e nos assentamentos urbanos. Os Isoseño 
vêem com maus olhos os dirigentes que vivem na cidade e se comportam como brancos. O que definitivamente um chiriguano ou um chané procura alcançar mediante um casamento hipergâmico é um status valorado na escala interétnica que - logicamente, de acordo com sua própria história - nunca pode ser concebido de modo igualitário. Os Isoseño, os Chiriguano e os Chané, se nos é permitida a expressão, casam-se com brancos para serem mais índios; e o casamento com um karai, nesta ótica, é o reverso da união com um yanaigua. Quando se renega ideologicamente a mestiçagem histórica com os Chané, o que se rejeita, da mesma maneira, mais que o hibridismo em si, é a identificação com uma posição social inferior.

\section{O fim dos paradoxos?}

Não existe nem jamais existiu uma dissolução absoluta da identidade coletiva no magma da mestiçagem, nem tampouco uma negação absoluta do fato da mistura tal como deixa entrever a ideologia; à deriva entre os dois extremos descobrimos antes uma discriminação seletiva, hierárquica, que fecha e abre as redes de aliança (militar, econômica, matrimonial) segundo o contexto e as conjunturas, e que em nenhum momento perde de vista a necessidade de afiançar a identidade étnica própria. Assim, o suposto desaparecimento dos Chiriguano deve-se mais ao pessimismo dos pesquisadores do que a uma realidade concreta. O dos Chané, por outro lado, inscreve-se na mesma trajetória histórica, e é compreendido por meio da representação ideológica de uma mestiçagem negada como tal. Sua rejeição é indissociável da negação da escravidão de outrora e de um status social inferior.

O grande mérito de Alter Ego foi a aplicação, em nossa opinião, do modelo dumontiano de assimetria como regulador de distintas relações sociais, interétnicas e de gênero. Faltou-lhe, no entanto, explorá-lo a fundo. A assimetria foi lida como a dominação - política, lingüística e cultural do elemento guarani sobre o elemento chané. Historicamente falando, esse processo efetivamente ocorreu e é marcadamente tangível nas fontes. Mas a absorção "canibal" dos Chané não foi tão completa e radical como se sustentou. Primeiro, a herança chané foi mais ou menos importante de acordo com as zonas e os grupos - sua vigência e sua força foram muito mais evidentes, por exemplo, no Isoso ou no Itiyuro do que nas regiões ava. Segundo, e sobretudo, não se limita à cultura material, mas impregna a totalidade da organização sociopolítica chiriguana. A assimetria que selou a "guaranização" dos tapï e marcou o "nascimento da identidade chiriguano" tem um forte sabor chané. Daí os paradoxos. Se a rejeição ao hibridismo 
parece-nos hoje ambígua é porque essa mesma rejeição é mestiça, filha das tensões implícitas na fusão entre a ideologia chané da estratificação social e da assimetria das relações de gênero guarani, e pai de uma nova identidade étnica que logo aprendeu a assenhorar-se - como verdadeiro kuimbae ("macho") — do lugar mais elevado da hierarquia nascente.

Recebido em 06 de abril de 2006

Aprovado em 09 de novembro de 2006

Tradução de Jorge Villela.

Isabelle Combès é pesquisadora do Institut Français d'Études Andines, Bolívia. E-mail: <kunhati@gmail.com>.

Diego Villar é pesquisador do CONICET, Argentina. E-mail: < villardieg@ gmail.com>.

\section{Notas}

${ }^{1}$ Para estudos que revelam distintas formas de interpretar a mestiçagem, cf. Gow 1991 e Pacheco de Oliveira 1998.

${ }^{2}$ Branislava Susnik seguramente foi a primeira a notar nas fontes a brutal desproporção entre os sexos dos conquistadores guarani e, portanto, sua necessidade de mulheres chané (1968:176).

${ }^{3}$ Sobre a integração dos Chané como kereimba, ver Saignes 1990: cap. 1. Arquétipo da masculinidade, os kereimbo - segundo as diferentes crônicas quireymba, quereimba, queremba, kereumbau ou kerembare - eram grupos de guerreiros especializados submetidos a ritos de iniciação, provas e treinamento que tonificavam sua capacidade bélica (Combès \& Saignes 1991:98-100).

${ }^{4}$ Ava significa "homem" em guarani e é a autodenominação tanto dos Ava-chiriguano como dos Simba — este último termo é um bolivianismo de origem quéchua que significa "trança" e designa os grupos Ava que mantêm mais ferreamente os costumes tradicionais. Descendentes de Chané "guaranizados", por último, os Isoseño da região do baixo Parapeti — são chamados tapii pelos Ava.

${ }^{5}$ A expressão "complexo chiriguano-chané" deve-se a Guillermo Magrassi (1968). Sob este rótulo, a tradição antropológica argentina aglutina todos os grupos de língua guarani da zona (Ava-chiriguano, Chané, Simba, Tapiete, Isoseño) sem 
aprofundar suas diferenças culturais.

${ }^{6}$ A etimologia que remete ao castigo do Inca foi exposta pela primeira vez por Alcaya em princípios do século XVII (Alcaya 1961 [c.1605]:56); o castigo pelo clima frio, por outro lado, foi exposto por Chomé em 1732 (1781 [1732]:242-243).

${ }^{7}$ Existe ainda outra etimologia, muito menos difundida e tão duvidosa quanto, que deriva o gentílico "chiriguano" da roupa chamada chiripa (Muller 1989:13).

${ }^{8}$ Sobre a construção estratégica de um "passado útil" e da memória seletiva entre os Isoseño e os Chané, veja-se respectivamente Combès 2005 e Bossert \& Villar 2005. Para um panorama comparativo mais amplo sobre a influência da memória paradoxal e seu domínio sobre as diversas figurações possíveis do contato interétnico, cf. Severi 2000 e Fausto 2005.

${ }^{9}$ Sobre a predileção dos Chiriguano pelos Chané para o rito canibal, veja-se, por exemplo, a Relación de la Orden [c. 1580], BN Madrid ms. 3044:315-316, e Lizárraga (1968 [c.1600]:83-84). Sobre os "resgates" de escravos chané pelos colonos brancos, pode-se consultar em particular González Maldonados 1965 [c. 1564], ANB CACh 12, 12-01-1580:2r; parecer do licenciado Bejarano em 1603 (ADI Montesclaros v.57, t.3, n.51 a 53); Informe de Miguel Ruiz de Bustillo, 1-01-1614, AGI Lima 144). Segundo Díaz de Guzmán, esta prática teve ao menos como conseqüência o paulatino abandono do canibalismo pelos Chiriguano: "De trinta anos a esta parte não executam as crueldades que costumavam fazer ao matá-los e comê-los, ao vendê-los aos Espanhóis em troca de espadas, machetes e todo gênero de ferramentas, cavalos e selas e outros apetrechos de guerra" (1979 [1617-1618]:78-79).

${ }^{10}$ Para uma introdução geral a alguns dos debates contemporâneos sobre a complementaridade e a assimetria entre os sexos entre os povos ameríndios, cf. Lorrain 2001 e os estudos compilados em Gregor e Tuzin 2001.

${ }^{11}$ Por exemplo, a direção isoseña censurou quando um de nós, em um trabalho preliminar sobre a história vernacular, evocou a histórica escravidão dos Chané.

12 Ao seguir as intuições pioneiras de Erland de Nordenskiöld (1920, 2002 [1912]) e Alfred Métraux (1930, 1932, 1934), Thierry Saignes elogiou a excepcional flexibilidade cultural dos Chiriguano, que lhes permitiu adotar elementos alheios (amazônicos, andinos, chaquenhos ou europeus) e forjar uma identidade mestiça que não se limitava ao legado guarani (1990:11). Entretanto, este autor nunca chegou a aprofundar a diversidade dessas influências culturais e interpretou toda a história chiriguana à luz das teses "guaranizantes" de Pierre e Hélène Clastres $(1974,1975)$.

${ }^{13}$ Resposta célebre do cacique chané Chindica diante dos franciscanos no rio Acero, em meados do século XVIII (Mingo de la Concepción 1981 [1791]:133).

${ }^{14}$ Entre os Guaná do Chaco oriental, o jesuíta Sanchez Labrador observava no final do século XVIII: "Estão os Chana divididos em capitanias. As principais são as dos caciques que são como régulos dos demais. Os capitães menores recaem nos 
parentes dos caciques, e assim estes como os caciques menores procuram continuar a mística nobreza de seu sangue casando-se entre si, os de igual hierarquia, para não se envilecer com a plebe" (Sánchez Labrador 1910 [1767], t.1, p.26). Para a etno-história de grupos Arawak do sul, como os Guana ou Terena no Chaco oriental, veja-se Susnik 1971:140-164. Para evidências de estratificação social entre os Terena, veja-se Cardoso de Oliveira 1960, 1961. Estas observações podem ser comparadas, por fim, com achados recentes que documentam comparativamente a predileção dos Arawak pela hierarquia, a chefia hereditária, a estratificação social e a faculdade de flexibilidade e adaptação (Heckenberger 1996 e 2002; Hornborg 1988:276-284 e 2005; Santos Granero 2002).

${ }^{15}$ É impossível mencionar em tão pequeno espaço todas as fontes históricas sobre os rincões chané. Remetemos, portanto, às bibliografias citadas em Combès 2005. Não existe, até esta dada, nenhum estudo histórico sobre o vale do Caipependi.

${ }^{16}$ Referimo-nos com esse título, é claro, à última obra de Thierry Saignes (1990).

${ }^{17}$ Nordenskiöld 1910 e 2002 [1912]:281; Métraux 1946; Susnik 1968:191-192; Dietrich 1986:201.

${ }^{18}$ Estas alianças mistas, naturalmente, são mais numerosas nos centros urbanos. Em Santa Cruz de la Sierra, 4,7\% dos casamentos une os Chiriguano a outros indígenas chaqueños e 20,6\% a brancos; entre os Chiriguano periurbanos agrupados na "capitania Zona Cruz", por outro lado, os casamentos com outros indígenas a custo atingem $2 \%$, enquanto $9,3 \%$ são celebrados com cônjuges brancos (Combès et alii 2003:61,68).

${ }^{19}$ Entre os 1.500 Chané do noroeste argentino, por exemplo, há apenas dois casos de casamentos entre homens chané e esposas wichi e toba-pilagá.

${ }^{20}$ Os preconceitos de indígenas e etnólogos reforçam-se mutuamente. Métraux herdou dos americanistas da escola de Gotemburgo a tese de que os Chiriguano e os Chané são "duas tribos que cultural e lingüisticamente têm pouco ou nada em comum com os povos chaqueños" (1946:197). Concorda com certos esquemas teóricos de traço evolucionista, mais ou menos explícitos, que colocam os povos agricultores acima dos caçadores-coletores nas escalas de desenvolvimento e complexidade cultural. Para além do argumento comparativo da posição dos Chiriguano e dos Chané como intermediários entre os povos de terras altas e baixas, Métraux volta quase obsessivamente às duas qualidades que a seu juízo evidenciam a "superioridade cultural" dos Chiriguano: sua limpeza e sua moral sexual (veja-se von Rosen 1924:224; Nordenskiöld 2002 [1912]:139, 208; Métraux 1935:417, 424-425 e 1948:473). Quanto às idéias dos próprios indígenas, já o padre Giannecchini notava que os Chiriguano se sentiam superiores aos Toba, Chorote e Mataco porque estes últimos não semeavam (1996 [1898]:296). Esta suposição parece encontrar algum eco entre os próprios povos chaqueños; ao menos entre os Wichi ocidentais, o termo para designar os brancos e os indígenas de idioma guarani é o mesmo, suwele (Rodrigo Montani \& John Palmer, comunicação pessoal). Sobre os diversos preconceitos étnicos dos Chiriguanos e dos Chané a respeito dos povos chaqueños, veja-se Giannecchini 1996 [1898]:359; Nino 
1912:213; Susnik 1968:17, 38, 193; Albó 1990:326; Bossert \& Villar 2004b: 9-10.

${ }^{21}$ Nana ou Yana designa em chiriguano o matagal ou monte baixo, enquanto kaa designa genericamente o monte e, em particular, a vegetação de maior altura. Em conseqüência, o termo yanaigua é um equivalente lingüístico da palavra kaaigua utilizada pelos Guarani do Brasil e do Paraguai.

${ }^{22} \mathrm{O}$ termo karai, ademais, remete ao nome de diferentes heróis civilizadores da mitologia guarani. Entre os Chiriguano, as referências não permitem afirmar que a palavra karai designasse, como em outros grupos Tupi ou Guarani mais orientais, os grandes xamãs. Os xamãs que encabeçaram as rebeliões messiânicas dos Chiriguano durante os séculos XVIII e XIX, por exemplo, eram chamados tumpa ("sagrado") e nunca karai (Combès 2005:95-96; ver também Susnik 1968 e Pifarré 1989).

${ }^{23}$ Para aprofundar o estudo dos diversos tipos de interpretações que os indígenas realizam sobre a superioridade tecnológica do branco, veja-se, no contexto específico dos Chiriguano e dos Chané, Villar 2005; e em um contexto comparativo mais amplo, Veber 1992, 1996 e Fausto 2001 e 2005. 


\section{Referências bibliográficas}

ALBÓ, Javier. 1990. Los Guaraní-Chiriguanos 3. La comunidad hoy. La Paz: CIPCA.

ALCAYA, Diego de. 1961 [c.1605]. "Relación cierta... a su Excelencia el señor Marqués de Montes Claros". In: Cronistas cruceños del Alto Perú Virreinal. Santa Cruz: UAGRM. pp. 47-68.

BOSSERT, Federico e VILLAR, Diego. 2004a. "La onomástica chané en clave etnográfica y comparativa". Acta Americana, 12(1):49-78.

2004b. Imágenes de la sociedad y de la naturaleza entre los Chané. Buenos Aires: Museo de Arte Precolombino/ Fundación Nicolás García Uriburu. 2005. "Aproximación al problema de la historia oral entre los Chané". Actas del Quinto Congreso Argentino de Americanistas. Buenos Aires: Sociedad Argentina de Americanistas. pp. 41-62.

CARDOSO DE OLIVEIRA, Roberto. 1960. O processo de assimilação dos Terena. Rio de Janeiro: Museu Nacional.

1961. "Marriage and terena tribal solidarity". América Indígena, 21(3): 233-252

CHOMÉ, Ignace. 1781. "Lettre du père Chomé, 21 juin 1732". Lettres édifiantes \& curieuses écrites des missions étrangères. Mémoires d'Amérique. Paris:Mérigot le Jeune. t.VIII, pp. 238-248.

CLASTRES, Hélène. 1975. La terre sans mal. Le prophétisme tupi-guarani. Paris : Seuil.

CLASTRES, Pierre. 1974. La société contre l'état. Paris : Ed. de Minuit.

COMAJUNCOSA, Antonio e CORRADO, Alejandro. 1884. El colegio francis- cano de Tarija y sus misiones. Noticias históricas recogidas por dos misioneros del mismo Colegio. Quaracchi: Tip. del Colegio de San Buenaventura.

COMBÈS, Isabelle. 2004a. "Chindica y Guaricaya, capitanes chané 'ynfieles de estas montañas'". Anuario del Archivo y Biblioteca Nacional de Bolivia, pp. 224-240. 2004b. "Tras la huella de los ñanaigua: de tapii, tapiete y otros salvajes en el Chaco boliviano". Bulletin de l'Institut Français d'Études Andines, 33(2):255-269. 2005. Etno-historias del Isoso. Chané y chiriguanos en el Chaco boliviano (siglos XVI a XX). La Paz: IFEA/PIEB.

e LOWREY, Kathleen. 2006

"Slaves without masters? Arawakan dynasties among the Chiriguano (Bolivian Chaco, XVI-XX centuries)". Ethnohistory, 53(4):689-714. et alii. 2003. Los indígenas olvidados. Los guaraní-chiriguanos urbanos y peri-urbanos en Santa Cruz de la Sierra. La Paz: PIEB. e SAIGNES, Thierry. 1991 Alter Ego. Naissance de l'identité chiriguano. Paris: EHESS/Cahiers de l'Homme. . 1995. "Chiriguana: nacimiento de una identidad mestiza". In: J. Riester (org.). Chiriguano. Santa Cruz: APCOB. pp. 25-221

COMBÈS, Isabelle e VILLAR, Diego. 2004. "Aristocracias chané. 'Casas' en el Chaco argentino y boliviano". Journal de la Société des Américanistes, 90(2):63-102.

DÍAZ DE GUZMÁN, Ruy. 1979 [16171618]. Relación de la entrada a los 
Chiriguanos. Santa Cruz: Fundación Cultural Ramón Darío Gutiérrez.

DIETRICH, Wolf. 1986. El idioma chiriguano. Madrid: Instituto de Cooperación Iberoamericana/ Ed. Cultura Hispánica.

DUMONT, Louis. 1966. Homo hierarchicus. Essai sur le système des castes. Paris: Gallimard/ NRF.

FAUSTO, Carlos. 2001. Inimigos fiéis. História, guerra e xamanismo na Amazônia. São Paulo: EDUSP. . 2005. "Se Deus fosse jaguar: canibalismo e cristianismo entre os guarani (séculos XVI-XX)". Mana. Estudos de Antropologia Social, 11(2):385-418.

GIANNECCHINI, Doroteo. 1996 [1898]. Historia natural, etnografía, geografía, lingüística del Chaco boliviano. Tarija: FIS/ Centro Eclesial de Documentación.

GONZÁLEZ MALDONADO, Ruy. 1965 [c.1564]. "Relación atribuida a Ruy Gónzalez Maldonado". In: M. J. de la Espada (org.), Relaciones geográficas de Indias. Madrid: Biblioteca de Autores Españoles, t. 1. pp. 398-401.

GOW, Peter. 1991. Of mixed blood: kinship and history in peruvian amazonia. Oxford: Clarendon Press. 2001. An amazonian myth and its history. Oxford: Oxford University Press.

GREGOR, Thomas e TUZIN, Donald (orgs.). 2001. Gender in Amazonia and Melanesia: an exploration of the comparative method. Berkeley: University of California Press.

HECKENBERGER, Michael. 1996. War and peace in the shadow of empire: sociopolitical change in the upper Xingu of southeastern Amazonia, A.D. 1400-2000. Tesis doctoral, Pittsburgh, University of Pittsburgh. . 2002. "Rethinking the arawakan diaspora: hierarchy, regiona- lity and the amazonian formative". In: J. Hill e F. Santos Granero (orgs.), Comparative arawakan histories. Rethinking languages family and cultural area in Amazonia. Urbana: University of Illinois Press. pp. 99-122.

HORNBORG, Alf. 1988. Dualism and hierarchy in lowland South America. Trajectories of indigenous social organization. Stockholm: Almqvist $\&$ Wiksell.

2005. "Ethnogenesis, regional integration, and ecology in prehistoric Amazonia. Toward a system perspective". Current Anthropology, 46(4):589-620.

HUGH-JONES, Stephen. 1988. "The gun and the bow. Myths of white men and indians". L'Homme, 28(106107):138-155.

LIZÁRRAGA，Reginaldo de. 1968 [c.1600]. Descripción breve de toda la tierra del Perú, Tucumán, Río de la Plata y Chile. Madrid: Biblioteca de Autores Españoles, 216. pp. 1-213.

LORRAIN, Claire. 2001. "The hierarchy bias and the equality bias: epistemological considerations on the analysis of gender". In: L. Rival e N. Whitehead (org.), Beyond the visible and the material: the amerindianization of society in the work of Peter Rivière. Oxford: Oxford University Press. pp. 263-295.

MAGRASSI, Guillermo. 1968. "El complejo chiriguano-chané". Censo Indígena Nacional. Tomo 2 (Provincias de Chaco, Formosa, Jujuy, Misiones, Salta y Santa Fe). Buenos Aires: Ministerio del Interior.

MATIENZO, Juan de. 1922 [1561]. "Carta a S. M., La Plata 20-10-1561". In: R. Levillier (org.), La audiencia de Charcas. Correspondencia de presidentes y oidores. Madrid: Colección de Publicaciones Históricas de la Biblioteca del Congreso Argentino, t. I. pp. 54-60. 
MAUSS, Marcel. 1980 [1924]. “Essai sur le don. Forme et raison de l'échange dans les sociétés archaïques". In: Sociologie et anthropologie. Paris: PUF. pp. 145-279.

MELIÀ, Bartolomeu. 1988. Los GuaraníChiriguanos 1: Nande Reko, nuestro modo de ser. La Paz: CIPCA.

MÉTRAUX, Alfred. 1930. "Études sur la civilisation des indiens Chiriguano". Revista del Instituto de Etnología de la Universidad de Tucumán, 1:295-493. 1932. "Mitos y cuentos de los indios chiriguano". Revista del $\mathrm{Mu}$ seo de La Plata, 33(9):119-184. 1934. "El estado actual de nuestros conocimientos sobre la extensión primitiva de la influencia guaraní y arawak en el continente sudamericano". Actas y trabajos científicos del $25^{\circ}$ Congreso Internacional de Americanistas (La Plata 1932). Buenos Aires: Coni. vol. I, pp. 181-190.

1935. "La mujer en la vida social y religiosa de los indios Chiriguano". Revista del Instituto de Etnología de la Universidad de Tucumán, 3:416-430. 1946. "Ethnography of the Chaco". In: J. Steward (org.), Handbook of south american indians. Washington: Smithsonian Institution. t. I, pp. 197-370.

1948. "Tribes of the eastern slopes of the bolivian Andes. Chiriguano and Chané". In: J. Steward (org.), Handbook of south american Indians. Washington: Smithsonian Institution. t. III, pp. 465-485.

MINGO DE LA CONCEPCIÓN, Manuel. 1981 [1791]. Historia de las misiones franciscanas de Tarija entre Chiriguanos. Tarija: Universidad Boliviana Juan Misael Saracho.

MORENO, Gabriel René. 1973. Catálogo del archivo de Mojos y Chiquitos. La Paz: Lib. Ed. Juventud (notas de H. Sanabria Fernández).
Müller, Franz. 1989. Etnografía de los guaraní del Alto Paraná. Buenos Aires: Centro Argentino de Etnología Americana.

NINO, Bernardino de. 1912. Etnografía chiriguana. La Paz: Tip. Comercial I. Argote.

NORDENSKIÖLD, Erland. 1910. "Sind die Tapiete ein guaranisienter Chacostamm?". Globus, XCVIII:181-186.

1920. The changes in the material culture of two indian tribes under the influence of new surroundings. Göteborg: Comparative Ethnographical Studies. vol. 2. 2002 [1912]. La vida de los indios. El Gran Chaco (Sudamérica). La Paz: APCOB/ Plural.

PACHECO DE OLIVEIRA, João. 1998. "Uma etnologia dos 'índios misturados'? Situação colonial, territorialização e fluxos culturais". Mana. Estudos de Antropologia Cultural, 4(1):47-77.

PIFARRÉ, Francisco. 1989. Los GuaraníChiriguanos 2. Historia de un pueblo. La Paz: CIPCA.

POLO DE ONDEGARDO, Juan. 1914 [1574]. "Informe sobre el origen y costumbres de los chiriguanos....". In: R. Mujía, Bolivia-Paraguay y Anexos. La Paz, APCOB. t. 2, pp. 82-98.

RELACIÓN DE LA ORDEN [c. 1580], BN Madrid, ms. 3044:315-316.

ROSEN, Eric von. 1924. Ethnographical research work during the swedish Chaco-Cordillera expedition 1901 1902. Estocolmo: C. E. Fritze Ltd.

SAIGNES, Thierry. 1974. Une frontière fossile: la cordillère chiriguano au XVIII siècle. Thèse de doctorat, EPHE, Paris, 2 tomos. 1990. Ava y Karai. Ensayos sobre la historia chiriguano (siglos XVI-XX). La Paz: HISBOL.

SÁNCHEZ LABRADOR, José. 1910 [C.1770]. El Paraguay católico. Buenos Aires: Imprenta de Coni Hermanos. 
SANTOS GRANERO, Fernando. 2002. "The arawakan matrix: ethos, language and history in native South America". In: J. Hill e F. Santos Granero (orgs.), Comparative arawakan histories. Rethinking languages family and cultural area in Amazonia. Urbana: Univ. of Illinois Press. pp. 25-50.

SCHWARTZ, Stuart e SALOMON, Frank. 1999. "New peoples and new kinds of people: adaptation, readjustment, and ethnogenesis in south american indigenous societies (Colonial Era)". In: F. Salomon e S. Schwartz (orgs.), The Cambridge history of the native peoples of the Americas. Cambridge/ New York: Cambridge University Press. vol. 3, parte 2, pp. 443-500.

SEVERI, Carlo. 2000. "Cosmologia, crise e paradoxo: da imagem de homens e mulheres brancos na tradição xamânica kuna". Mana. Estudos de Antropologia Social, 6(1):121-155.

SUÁREZ DE FIGUEROA, Lorenzo. 1965 [1586]. "Relación de la ciudad de Santa Cruz de la Sierra". In: M. J. de la Espada, Relaciones geográficas de Indias. Madrid: Biblioteca de Autores Españoles, t. 1. pp. 402-406.

SUSNIK, Branislava. 1968. Chiriguanos I. Dimensiones etnosociales. Asunción: Museo Etnográfico Andrés Barbero.

. 1971. El indio colonial del Paraguay III-1. El chaqueño: Guaycurúes y Chanes-Arawak. Asunción: Museo Etnográfico Andrés Barbero.

VEBER, Hanna. 1992. "Why indians wear clothes: managing identity across an ethnic boundary". Ethnos, 57:51-60.

. 1996. "External inducement and non-westernization in the uses of the Ashéninka Cushma". Journal of Material Culture, 1:155-182.

VILLAR, Diego. 2005. "Indios, blancos y perros", Anthropos, 100(2):495-506.

\section{Siglas de arquivos utilizados}

ADI - Arquivo do Duque Infante Montesclaros (Madrid)

AGI - Arquivo Geral das Índias, Sevilha Lima Audiência de Lima

ABN - Arquivo Nacional da Bolívia, Sucre

CACh - Correspondência da Audiência de Charcas

BN - Biblioteca Nacional 
Resumo

O ponto de partida deste artigo é a tese desenvolvida em 1991 por Isabelle Combès e Thierry Saignes sobre o nascimento da etnia e da identidade chiriguano, mestiças "em essência". A relação que os Chiriguano e os Chané mantêm com a mestiçagem parece, no entanto, paradoxal. Embora sejam considerados exemplos paradigmáticos de mestiçagem ameríndia, algumas visões contemporâneas sentenciam a dissolução da etnia devido precisamente à mestiçagem com os brancos. Ao mesmo tempo, os próprios Chiriguano rejeitam atualmente qualquer idéia de mistura, proclamando-se apenas "guarani". A partir de um duplo estudo de caso no Isoso boliviano e no noroeste argentino, relativiza-se o postulado da completa absorção dos Chané pelo conjunto Chiriguano; depois são analisados os diferentes tipos de mestiçagem existentes e sua relação com um esquema assimétrico que cria uma verdadeira escala de valores entre diferentes etnias. Finalmente, sugere-se que a ambivalência ideológica que envolve a mestiçagem se deve ao fato de que ela é precisamente uma construção híbrida, produto da fusão entre as ideologias chané e guarani.

Palavras-chave: Arawak, Guarani, Chiriguano, Chané, Chaco, Mestiçagem.

\section{Abstract}

The starting point of this article is the thesis developed in 1991 by Isabelle Combès and Thierry Saignes on the birth of Chiriguano ethnicity and identity, both mixed 'in essence.' The Chiriguano and the Chané appear to maintain a somewhat paradoxical relationship with miscegenation, however. Although considered paradigmatic examples of Amerindian miscegenation, some contemporary views anticipate the dissolution of the ethnic group precisely because of its mixture with whites. At the same time, the Chiriguano themselves reject any idea of mixture, proclaiming themselves to be simply 'Guarani.' Based on a double case study of the Bolivian Isoso and the Argentinean Northwest, the article casts doubt on the idea of the complete absorption of the Chané by the Chiriguano complex; it then analyzes the different types of miscegenation in existence and their relation to an asymmetrical schema that creates a scale of values between different ethnic groups. Finally, the authors suggest that the ideological ambivalence surrounding miscegenation is precisely due to the fact that it is a hybrid construct, the product of the fusion between Chané and Guarani ideologies.

Key words: Arawak, Guarani, Chiriguano, Chané, Chaco, Miscegenation. 